\title{
TBX18 gene induces adipose-derived stem cells to differentiate into pacemaker-like cells in the myocardial microenvironment
}

\author{
MEI YANG ${ }^{1,2^{*}}$, GE-GE ZHANG $^{1,2^{*}}$, TENG WANG ${ }^{1,2}$, XI WANG $^{1,2}$, YAN-HONG TANG $^{1,2}$, HE HUANG $^{1,2}$, \\ HECTOR BARAJAS-MARTINEZ ${ }^{3}$, DAN HU ${ }^{1-3}$ and CONG-XIN HUANG ${ }^{1,2}$ \\ ${ }^{1}$ Department of Cardiology, Renmin Hospital of Wuhan University; ${ }^{2}$ Cardiovascular Research Institute, \\ Wuhan University, Wuhan, Hubei 430060, P.R. China; ${ }^{3}$ Department of Molecular Genetics, \\ Masonic Medical Research Laboratory, Utica, NY 13501, USA
}

Received October 14, 2015; Accepted August 31, 2016

DOI: 10.3892/ijmm.2016.2736

\begin{abstract}
T-box 18 (TBX18) plays a crucial role in the formation and development of the head of the sinoatrial node. The objective of this study was to induce adipose-derived stem cells (ADSCs) to produce pacemaker-like cells by transfection with the TBX18 gene. A recombinant adenovirus vector carrying the human TBX18 gene was constructed to transfect ADSCs. The ADSCs transfected with TBX18 were considered the TBX18-ADSCs. The control group was the GFP-ADSCs. The transfected cells were co-cultured with neonatal rat ventricular cardiomyocytes (NRVMs). The results showed that the mRNA expression of TBX18 in TBX18-ADSCs was significantly higher than in the control group after $48 \mathrm{~h}$ and 7 days. After 7 days of co-culturing with NRVMs, there was no significant difference in the expression of the myocardial marker cardiac troponin I (cTnI) between the two groups. RT-qPCR and western blot analysis showed that the expression of HCN4 was higher in the TBX18-ADSCs than in the GFP-ADSCs. The $I_{f}$ current was detected using the whole cell patch clamp technique and was blocked by the specific blocker $\mathrm{CsCl}$. Human induced pluripotent stem cell-derived cardiomyocytes (hiPSCMs) showed approximately twice the current density compared with the ADSCs. Our study indicated that the TBX18 gene induces ADSCs to differentiate into pacemaker-like cells in the cardiac microenvironment. Although further experiments are required in order to assess safety and efficacy prior to implementation in clinical practice, this technique may provide new avenues for the clinical therapy of bradycardia.
\end{abstract}

Correspondence to: Professor Cong-Xin Huang, Department of Cardiology, Renmin Hospital of Wuhan University, 238 Jiefang Road, Wuchang, Wuhan, Hubei 430060, P.R. China

E-mail: huangcongxin@vip.163.com

\section{${ }^{*}$ Contributed equally}

Key words: biological pacemaker, TBX18, adipose-derived stem cells, co-culture, stem cells

\section{Introduction}

Gene-based and cell-based therapies are effective approaches for engineering biological pacemakers. Stem cells are candidates that are capable of carrying genes to achieve a combination of gene- and cell-based precision therapy. Adipose-derived stem cells (ADSCs) have many advantages; they are available in abundance using a simple collection method and do not cause non-immune rejection. ADSCs have multilineage differentiation potential (1). Several studies have shown that ADSCs possess the ability to differentiate into cardiomyocytes in vitro and in vivo (2-4). One study investigated the pacemaker activity of cells derived from ADSCs in semi-solid methylcellulose medium (5).

The development of the sinoatrial node is regulated by many transcription factors including those of the T-box (TBX) family. TBX18 is a member of the TBX family. In the early stages of embryonic development, epicardial $\mathrm{TBX} 18^{+}$mesenchymal progenitor cells migrate to the head region of the sinoatrial node. The gene tracer technique has shown that the majority of cells in the head of the sinoartial node are derived from TBX $18^{+}$progenitor cells (6). A study showed that $\mathrm{TBX} 18^{+}$mesenchymal progenitor cells are capable of differentiating into ventricular septal and left ventricular myocardial cells (7), which remains controversial (8). In homozygous TBX18-mutant and TBX18-deficient mouse fetuses, the head of the sinoatrial node was found to be significantly reduced, and the sinoatrial node and atrial myocardial layer were found to be disorganized (6). However, no abnormal changes were observed in the left ventricular myocardium.

Kapoor et al (9) demonstrated that focal TBX18 transduction reprogrammed ventricular myocytes into pacemaker cells that are indistinguishable from genuine sinoatrial node cells, both physiologically and morphologically. In vivo experiments showed that TBX18 produced biological pacemaker activity in the ventricle and high septal region by percutaneous gene transfer $(9,10)$.

To date, no studies have reported the effects of TBX18 on stem cells, to the best of our knowledge. This study used rat ADSCs as seed cells. ADSCs were transfected with TBX18 and were co-cultured with neonatal rat ventricular cardiomyocytes (NRVMs) in order to examine whether ADSCs are capable of differentiating into pacemaker-like cells in vitro. 


\section{Materials and methods}

Isolation and culture of ADSCs. All experimental procedures were conducted in accordance with the Institutional Guidelines for the Care and Use of Laboratory Animals at Wuhan University (Wuhan, China) and conformed to the National Institutes of Health Guide for the Care and Use of Laboratory Animals. Ethics approval was provided by the Ethics Committee of Wuhan University. One adult male Sprague Dawley (SD) rat, aged 4 weeks, was anesthetized with an intraperitoneal injection of $3 \%$ pentobarbital sodium $(30 \mathrm{mg} / \mathrm{kg}$ ). Adipose tissue was bilaterally obtained from the inguen of the rat and washed with sterile phosphate-buffered saline (PBS). The adipose tissue was then cut into $1 \mathrm{x} 1 \mathrm{~mm}^{3}$ pieces after the careful removal of blood vessels and fascia. The tissue pieces were digested by incubation with $1 \mathrm{mg} / \mathrm{ml}$ collagenase type I (Sigma, St. Louis, MO, USA) for $1 \mathrm{~h}$ at $37^{\circ} \mathrm{C}$ with constant shaking. The cell suspension was centrifuged at $1,000 \mathrm{xg}$ for $10 \mathrm{~min}$. The pellet was resuspended in Dulbecco's modified Eagle's medium (DMEM)/F12 supplemented with $10 \%$ fetal bovine serum (FBS) (Gibco, Carlsbad, CA, USA) and $1 \%$ penicillin/streptomycin (Invitrogen, Carlsbad, CA, USA). The cell inoculation density was $5 \times 10^{6}$ nucleated cells/100-mm tissue culture dish (11). Following $48 \mathrm{~h}$ of culture in an incubator at $37^{\circ} \mathrm{C}$ with a $5 \% \mathrm{CO}_{2}$ atmosphere, the medium was removed and replaced with fresh medium. When the cells reached $80-90 \%$ confluence, they were passaged using $0.25 \%$ trypsin (Gibco). Cells of passages 3-5 were used for all subsequent analyses.

Adenovirus construction and purification. pHBAd-MCMVGFP (Hanbio, Shanghai, China) was digested with BamHI and NotI. The ORF sequence of the human TBX18 gene (GenScript, Nanjing, China) was amplified by polymerase chain reaction (PCR). After enzyme digestion, gel extraction was performed. The digested fragment and vector were ligated to form pHBAd-MCMV-GFP-TBX18, which was then transformed into competent DH5 $\alpha$ cells (Tiangen, Beijing, China). Positive clones were identified by liquid sequencing. Bacteria in liquid in the logarithmic growth phase were incubated at $37^{\circ} \mathrm{C}$ in LB culture medium with shaking at $300 \mathrm{xg}$ overnight. Large scale preperation of recombinant plasmid was conducted using the Plasmid Midi Preparation kit (Beijing CW Biotech Co., Ltd., Beijing, China). Cells (293; from our laboratory) were transfected with pHBAd-MCMV-GFP-TBX18 and the backbone vector $\mathrm{pHBAd}-\mathrm{BHG}$ using Lipofilter $^{\mathrm{TM}}$ (both from Hanbio). The supernatant was harvested after virus amplification. Ad-GFP and Ad-TBX18 were measured as $1 \mathrm{X} 1010 \mathrm{PFU} / \mathrm{ml}$ and were preserved at $-80^{\circ} \mathrm{C}$.

ADSCs transfected with TBX18. ADSCs of passages 3-5 were removed from the culture dishes by digestion. A cell suspension was prepared and then inoculated onto 6-well plates. When cell confluence reached 70-80\%, Ad-TBX18 in DMEM/F12 was added to the cells at different multiplicity of infection (MOI) values. The control group was treated with Ad-GFP. After a $2 \mathrm{~h}$ incubation period, the medium was replaced with fresh complete medium. The cells were observed under a light microscope and a fluorescent microscope (BX51 systems, Olympus, Tokyo, Japan).
Flow cytometric analysis. ADSCs were transfected with different MOI values $(0,10,20,50,80,100$ and 1,000). The transfected cells were digested with $0.25 \%$ trypsin at $48 \mathrm{~h}$ and 7 days after transfection. The cell suspension was centrifuged at $800 \mathrm{x} \mathrm{g}$ for $5 \mathrm{~min}$ and then washed with PBS twice. The cell density was $1 \times 10^{6} / \mathrm{ml}$. Non-transfected cells served as a negative control. The percentage of green fluorescent protein-positive cells was detected by flow cytometric analysis (Becton-Dickinson, Franklin Lakes, NJ, USA).

Isolation and culture of NRVMs. Cardiomyocytes were isolated from ten 1-2-day-old SD rats and then washed three times with PBS at a temperature of $4^{\circ} \mathrm{C}$. Heart tissue was cut into $1 \mathrm{~mm}^{3}$ pieces and digested with $0.125 \%$ trypsin at $37^{\circ} \mathrm{C}$ for $10 \mathrm{~min}$ and the supernatant was discarded. The pieces were then digested with mixed liquor containing $0.125 \%$ trypsin and $0.08 \%$ collagenase II (Sigma) five times at $37^{\circ} \mathrm{C}$ for $5 \mathrm{~min}$. The digested tissue pieces were then centrifuged at $1,000 \mathrm{x} \mathrm{g}$ for $10 \mathrm{~min}$. The pellets were resuspended with fresh high-glucose DMEM supplemented with $10 \%$ FBS and $1 \%$ penicillin/streptomycin, and filtered through a 200 mesh sieve. The resuspended cells were then inoculated into a culture dish for $1.5 \mathrm{~h}$ to isolate the cardiomyocytes from the fibroblasts. After $1.5 \mathrm{~h}$, the cardiomyocytes were gently sucked out of the culture dish and were seeded into 6-well plates. The cell concentration was adjusted to $5 \times 10^{5} / \mathrm{ml}$. During the first $48 \mathrm{~h}$ after seeding, $0.1 \mathrm{mmol} / 1$ bromodeoxyuridine (BrdU; Sigma) was used to inhibit the mitosis of fibroblasts.

Co-culture of transfected ADSCs with NRVMs. ADSCs were transfected with Ad-TBX18 and Ad-GFP for $48 \mathrm{~h}$, and used to prepare a cell suspension, and then co-cultured with NRVMs at a ratio of 1:5 or 1:10. The complete culture medium was replaced every two days.

Reverse transcription-quantitative polymerase chain reaction $(R T-q P C R)$. Total RNA was extracted from the transfected ADSCs and co-culture systems after one week using TRIzol ${ }^{\circledR}$ reagent (Invitrogen). Quantitative PCR was performed to evaluate the mRNA expression of human TBX18 and hyperpolarization activated cyclic nucleotide gated potassium channel 4 (HCN4). Isolated RNA (2 $\mu \mathrm{g})$ was converted into cDNA using the First Strand cDNA Synthesis kit (Toyobo, Tokyo, Japan). The primers used for PCR amplification were synthesized by Invitrogen Biotechnology (Shanghai, China) and are presented in Table I. RT-qPCR was performed using the StepOne ${ }^{\mathrm{TM}}$ Real-Time PCR system (Life Technologies, Carlsbad, CA, USA). The reactions were then conducted using the SYBR ${ }^{\circledR}$ Premix Ex Taq TM II (Takara Bio, Japan). Semilog amplification curves were analyzed using the $2-\Delta \Delta \mathrm{Ct}$ comparative quantification method and the expression of each gene was normalized to GAPDH.

Western blot analysis. TBX18-ADSCs and GFP-ADSCs co-cultured with NRVMs and NRVMs cultured alone were plated on 6-well culture dishes. The cells were harvested using RIPA lysis buffer (Beyotime Institute of Biotechnology, Haimen, China). Equal amounts of protein were loaded onto a gel for sodium dodecyl sulphate-polyacrylamide gel electrophoresis (SDS-PAGE), and the separated proteins were 
Table I. PCR primers used in this study.

\begin{tabular}{|c|c|c|c|}
\hline Gene & Primer & Reaction condition & Product size (bp) \\
\hline H-ТВX18 & $\begin{array}{ll}\text { Sense: } & \text { 5'-ACGTCATCCGTAAAGACTGTGG-3' } \\
\text { Antisense: 5'-AGTCCGTAGTGATGGTCGCC-3' }\end{array}$ & 33 cycles at $54^{\circ} \mathrm{C}$ in $1 \mathrm{mM} \mathrm{MgCl} 2$ & 251 \\
\hline HCN4 & $\begin{array}{ll}\text { Sense: } & \text { 5'-AACCTGGGGGCTGGACAGA-3' } \\
\text { Antisense: } & \text { 5-'CTGGGCAGCCTGTGGAGAG-3' }\end{array}$ & 33 cycles at $58^{\circ} \mathrm{C}$ in $1 \mathrm{mM} \mathrm{MgCl}{ }_{2}$ & 462 \\
\hline GAPDH & $\begin{array}{ll}\text { Sense: } & \text { 5'-GCCATCAACGACCCCTTCAT-3' } \\
\text { Antisense: } & \text { 5'-TTCACACCCATCACAAACAT-3' }\end{array}$ & 33 cycles at $56^{\circ} \mathrm{C}$ in $1 \mathrm{mM} \mathrm{MgCl}_{2}$ & 315 \\
\hline
\end{tabular}

H-TBX18, human T-box 18; HCN4, hyperpolarization activated cyclic nucleotide gated potassium channel 4.

transferred to a nitrocellulose membrane, and then incubated with the primary antibodies against HCN4 (ab32675; Abcam, Cambridge, MA, USA) overnight at $4^{\circ} \mathrm{C}$. The primary antibodies were detected by incubating the membrane with horseradish peroxidase-conjugated secondary antibodies (KPL, 14-16-06, 074-1506) raised in the appropriate species, and then performing enhanced chemiluminescence detection (ECL; Beyotime Institute of Biotechnology). The level of GAPDH was used to normalize the signal intensities.

Immunostaining studies. TBX18-ADSCs and GFP-ADSCs were co-cultured with NRVMs on gelatin-coated coverslips in 6-well culture dishes. The cell cultures were washed with PBS and fixed with $4 \%$ paraformaldehyde. Following permeabilization with $0.1 \%$ Triton $\mathrm{X}-100$, the cells were incubated with the primary antibody anti-cardiac troponin I (cTnI; ab19615; 1:200; Abcam) overnight at $4^{\circ} \mathrm{C}$. The secondary antibodies Cy3-conjugated Affinipure goat anti-rabbit IgG (111-165-003) and FITC-AffiniPure $F\left(a b^{\prime}\right) 2$ Fragment goat anti-mouse IgG (115-096-006) (both from Jackson ImmunoResearch Laboratories, Inc., West Grove, PA, USA)were used to detect cTnI. 4',6-Diamidino-2-phenylindole (DAPI) was used to visualize the nuclei. The cells were observed under a fluorescent microscope (Leica, Wetzlar, Germany). We randomly selected three visual fields in three different cell isolates to observe the positive rates of cTnI detection.

Electrophysiological recordings. Co-cultured systems were plated on gelatin-coated coverslips in 24-well culture dishes. The whole cell patch clamp technique was used to record the $\mathrm{I}_{\mathrm{f}}$ current after 5-7 days of co-culture. The cells were previously incubated with $180 \mu \mathrm{mol} / 1$ 2-aminoethoxydiphenyl borate (2-APB; Sigma) for 15 min. 2-APB blocks Cx40, Cx43 and Cx45 and thus, blocks the electrical conduction between cells $(12,13)$. We selected smooth and plump cells to record current. The impedance of the fluid filled electrode was 3 to $4 \mathrm{M} \Omega$. The experiments were performed using an Axon patch-clamp amplifier 700B (Molecular Devices, Sunnyvale, CA, USA). A digital 700AD/DA converter and 6.0.4 pClamp (both from Axon Instruments, Union City, CA, USA) were used for recording and analyzing the data. The bath solution has the following components (in mmol/l): $140 \mathrm{NaCl}, 5.4 \mathrm{KCl}, 1.0 \mathrm{MgCl}_{2}, 1.8 \mathrm{CaCl}_{2}$, 1.0 $\mathrm{BaCl}_{2}, 5.5 \mathrm{HEPES}, 5.0$ glucose ( $\left.\mathrm{pH} 7.3\right)$; the pipette solution contained the following (in mmol/l): $20 \mathrm{KCl}, 125 \mathrm{~K}$-gluconate,
1.0 $\mathrm{MgCl}_{2}, 5.0 \mathrm{NaCl}, 10 \mathrm{HEPES}, 5 \mathrm{~K}_{2} \mathrm{ATP}$ (pH 7.3). The whole cell recording mode was used to record $\mathrm{I}_{\mathrm{f}}$. The Clampex program was applied to the sample. The sampling frequency was $10 \mathrm{kHz}$, and the filtering rate was $5 \mathrm{kHz}$. The resting potential was $-30 \mathrm{mV}$ and decreased to $-140 \mathrm{mV}$ with each sweep $10 \mathrm{mV}$, then returned to the resting potential. $\mathrm{CsCl}(4 \mathrm{mmol} / \mathrm{l})$ was administered to detect the change in $\mathrm{I}_{\mathrm{f}}$. Commercial human induced pluripotent stem cell-derived cardiomyocytes (hiPS-CMs) cell line (CDI, Madison, WI, USA) were used to compared the macroscopic current using the whole cell patch clamp technique with ADSCs. Cells were held at $-30 \mathrm{mV}$ before eliciting a $2 \mathrm{sec}$ hyperpolarization pulse from -140 to $-40 \mathrm{mV}$ to measure $\mathrm{I}_{\mathrm{f}}$.

Statistical analysis. The reported data are expressed as the means \pm SD. The statistical significance of the differences between two groups was determined using the Student's t-test. Comparisons among three groups were made using one-way analysis of variance (ANOVA). A P-value of $<0.05$ was considered to indicate a statistically significant difference.

\section{Results}

Optimum MOI value of transfection and expression of the TBX18 gene. The ADSCs appeared fibroblast-like and showed parallel growth (Fig. 1A). The ADSCs were transfected with GFP and the TBX18 gene at different MOI values. After successful transfection, the ADSCs exhibited green fluorescence (Fig. 1B). Flow cytometric analysis showed that the transfection efficiency was $>70 \%$ at a MOI value $\geq 50$ (Fig. 1C). The transfection efficiency was $75.7 \pm 5.6 \%$ at an MOI of 50 (Fig. 1C). At an MOI of 80, the fluorescent cells appeared as roundish cells with vacuoles in the cytoplasm. This phenomenon was more severe at an MOI of 1000. The optimum MOI value of transfection was 50 and was adopted in this study. The mRNA expression of TBX18 in the TBX18-ADSCs group was significantly higher than that in the control group at $48 \mathrm{~h}$ and 7 days after transfection (Fig. 1D). The results showed that TBX18 is stably expressed in ADSCs.

Cardiomyogenic differentiation confirmed by immunocytochemical analysis. The expression of the myocardial specific marker cTnI was detected by immunofluorescence at 7 days after transfection and co-culture. The NRVMs and cardiac muscle-like cells were all positive for cTnI 


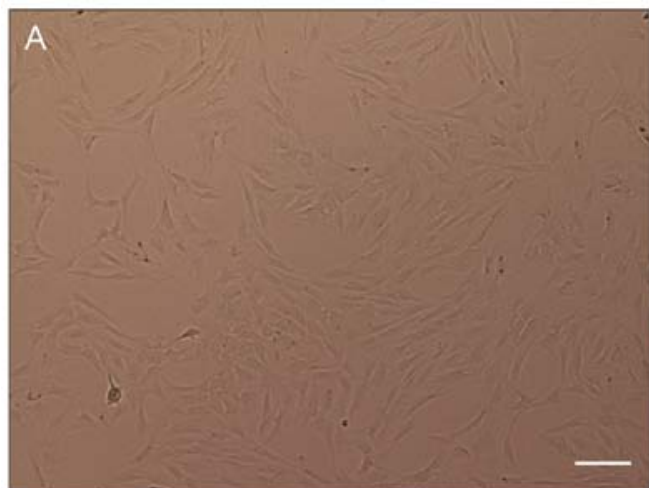

C

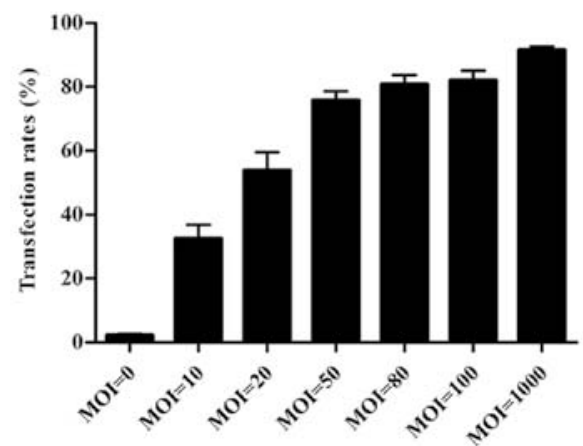

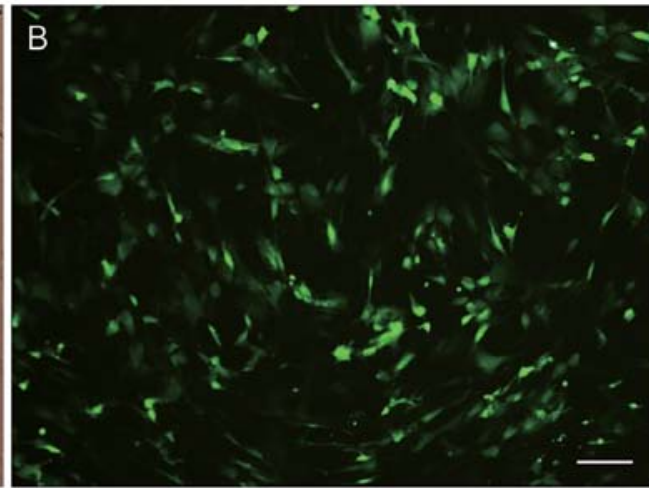

D

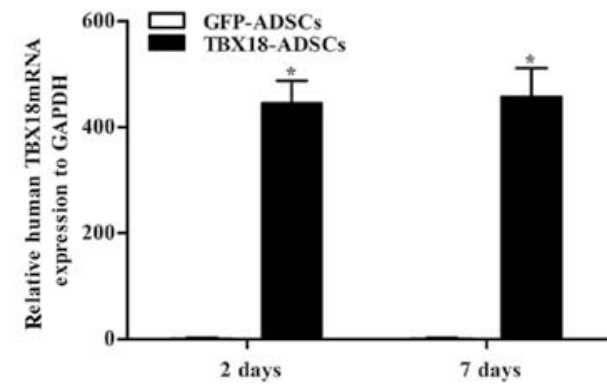

Figure 1. Transfection rate and expression of T-box 18 (TBX18). (A) Adipose-derived stem cells (ADSCs) in passage 3 observed under a light microscope. (B) TBX18-ADSCs observed under a fluorescence microscope. (C) Transfection rate of different multiplicity of infection (MOI) values detected by flow cytometric analysis. (D) Expression of TBX18 mRNA at two and 7 days after transfection. Scale bar, $200 \mu \mathrm{m}$. "P<0.05 vs. GFP-ADSCs group.

expression. Cells positive for cTnI expression were found in the GFP-ADSCs-NRVMs and the TBX18-ADSCs-NRVMs groups (Fig. 2A-F). The number of positive cells was not significantly different between the two groups. Fluorescence microscopy revealed that the number of positively transfected ADSCs at one week was $28.6 \pm 5.8$ and $26.6 \pm 5.9 \%$ in the GFP-ADSCs-NRVMs and TBX18-ADSCs-NRVMs, respectively (Fig. 2G). cTnI expression was observed in transfected ADSCs that were not co-cultured with NRVMs. At 5-7 days of co-culture, the transfected cells appeared to form connections with the adjacent NRVMs and synchronous beating was generated (Fig. 3).

Expression of the pacemaker channel HCN4. The expression of HCN4 was detected by RT-qPCR and western blot analysis. NRVMs served as the positive control group. The protein level of HCN4 in the TBX18 group was significantly higher than that in the control group and NRVMs after 7 days of co-culture (Fig. 4A and B). The results of RT-qPCR revealed that the mRNA expression of HCN4 in the TBX18 group was higher than that in the GFP group (Fig. 4C).

Patch clamp detection of $I_{f}$ current. Green fluorescent cells detected by the patch clamp method were treated with 2-ABP to block electric coupling (Fig. 5A). The $\mathrm{I}_{\mathrm{f}}$ current was detected in the TBX18-ADSCs group (Fig. 5B), but not in the control group. The TBX18-ADSCs had an inward current ( 1/20 cells) that was activated by the hyperpolarizing steps from $-40 \mathrm{mV}$. The maximum activation potential of the $I_{f}$ current was $\sim-140 \mathrm{mV}$. The maximum current density of active voltage was
$-5.43 \pm 1.36 \mathrm{pA} / \mathrm{pF}(\mathrm{n}=4)$ (Fig. 5C). The current was completely inhibited by $4 \mathrm{mmol} / \mathrm{l}$ CsCl.Macroscopic $\mathrm{I}_{\mathrm{f}}$ currents in a single beating hiPSCM (Fig. 6A) showed a greater $\mathrm{I}_{\mathrm{f}}$ current of $-13.1 \pm 1.0 \mathrm{pA} / \mathrm{pF}(\mathrm{n}=4)$ (Fig. 6B) compared with the TBX18-ADSCs.

\section{Discussion}

The constructed vector of biological pacing mainly contained mature cardiomyocytes and stem cells. Different interventions were then applied to the carrier in order to achieve biological pacing. Recently, related studies have examined the effect of the early embryonic transcription factor TBX18 on the mature myocardium $(9,10)$. In the present study, we found that rat ADSCs transfected with the TBX18 gene are capable of differentiating into pacemaker-like cells after being co-cultured with NRVMs. This design of this study took into account the developmental mechanism of the sinoatrial node and the cellular origin of sinoatrial node formation. We performed a direct intervention at the beginning of stem cell differentiation by transfecting cells with the transcription factor TBX18. The transfected cells were co-cultured with NRVMs to induce differentiation into pacemaker-like cells. We used this method due to the fact that at the beginning of differentiation more stem cells are inclined to differentiate into sinoatrial node cells.

Some researchers have achieved biological pacing using transcription factors such as short stature homeobox 2 (SHOX2) and TBX3. Previous researchers have shown that both SHOX2 and TBX3 increased the efficiency of the differentiation of 

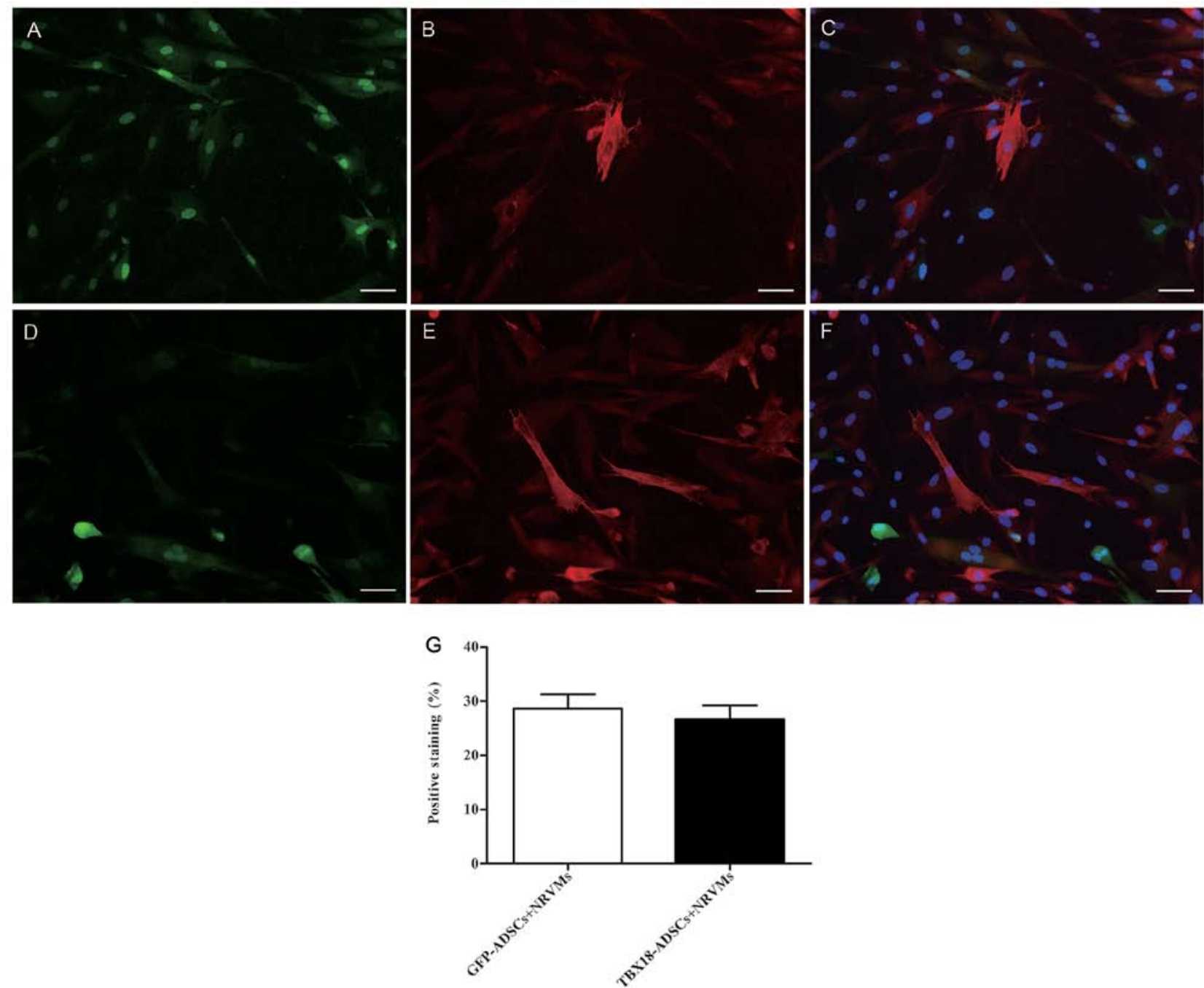

Figure 2. Expression of cardiac troponin I (cTnI) after co-culture for 7 days. (A) GFP-ADSCs detected by immunofluorescence assay (green). (B) Representative positive staining of cTnI (red). (C) Overlay of images (A and B). The nuclei were counterstained with DAPI (blue). (D) T-box 18 (TBX18)-ADSCs detected by immunofluorescence assay (green). (E) Representative positive staining of cTnI (red). (F) Overlay of images (D and E). The nuclei were counterstained with DAPI (blue). (G) Degree of positive staining of cTnI in TBX18-ADSCs and GFP-ADSCs. Scale bar, $50 \mu \mathrm{m}$.

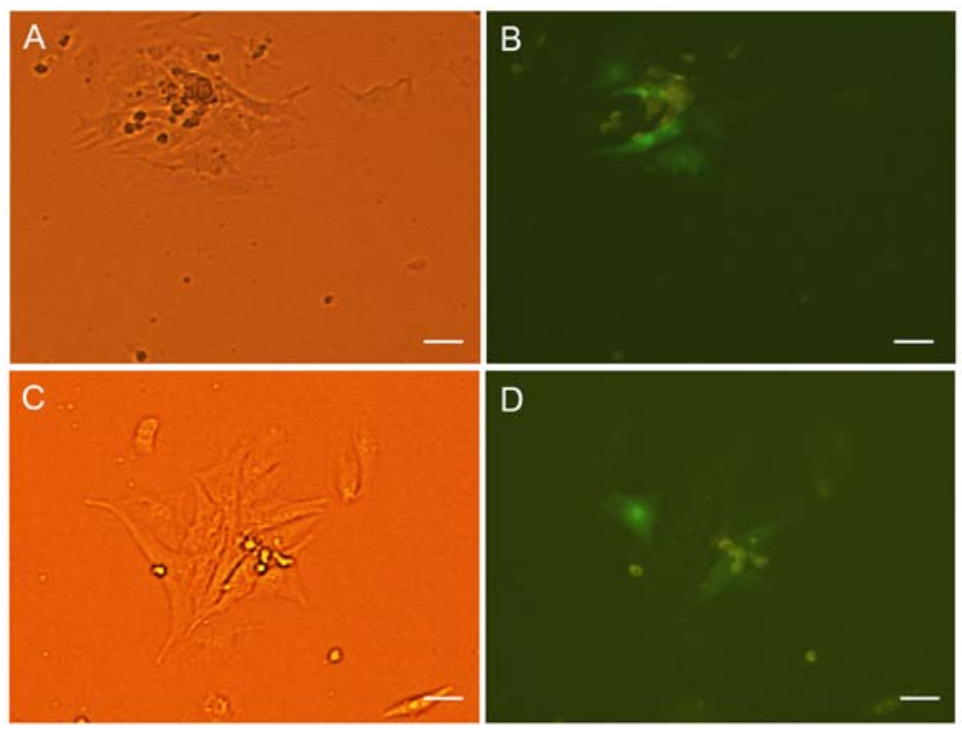

Figure 3. (A) Transfected adipose-derived stem cells (ADSCs) form connections with neonatal rat ventricular cardiomyocytes (NRVMs) and generate synchronous beating. (A) Observed under a light microscope in GFP-ADSCs group. The beating rate is $56 \mathrm{bpm}$. (B) Observed under a fluorescence microscope in GFP-ADSCs group. (C) Observed under a light microscope in T-box 18 (TBX18)-ADSCs group. The beating rate is 75 bpm. (D) Observed under a fluorescence microscope in TBX18-ADSCs group. Scale bar, $100 \mu \mathrm{m}$. 

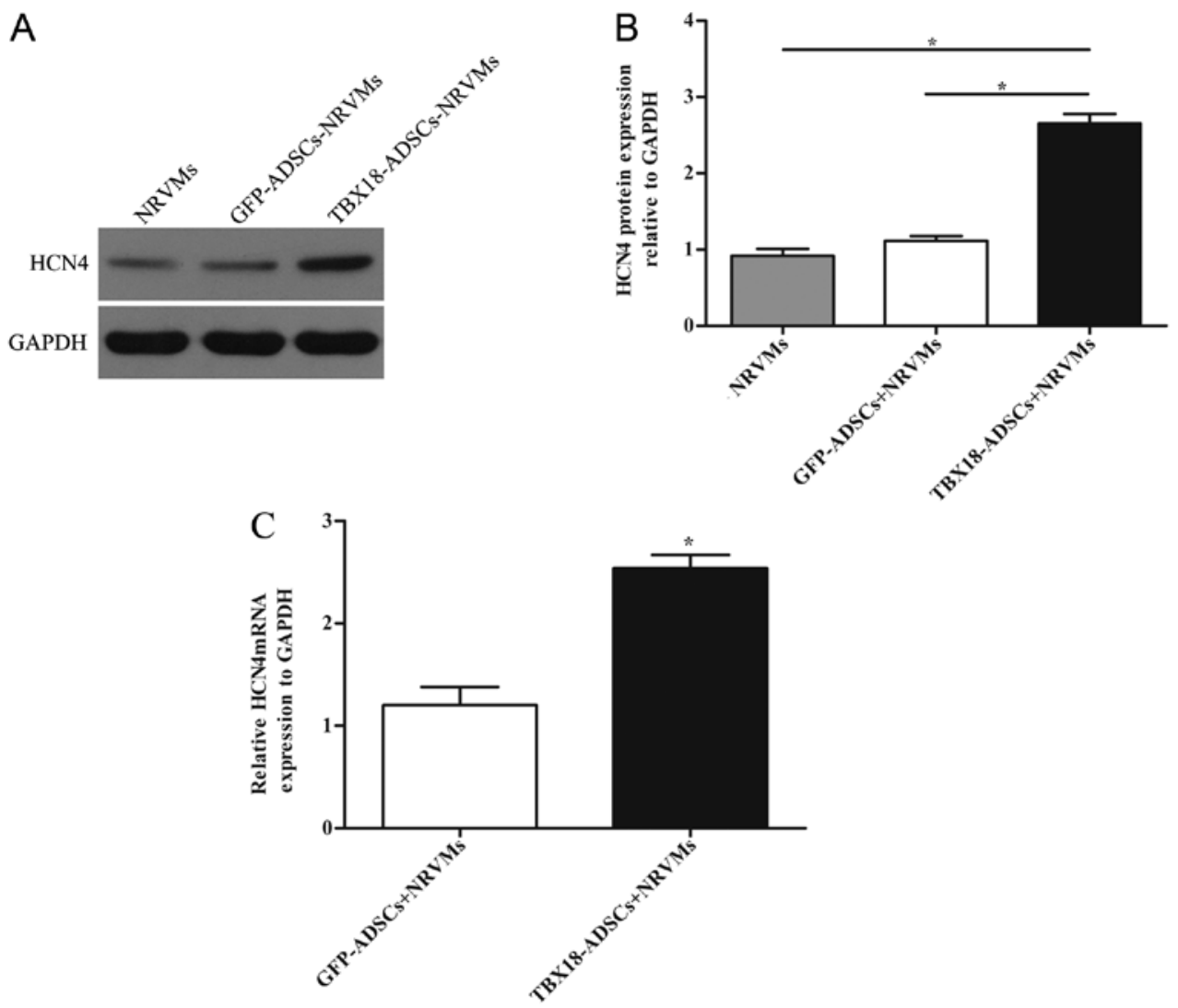

Figure 4. Expression of hyperpolarization activated cyclic nucleotide gated potassium channel 4 (HCN4) after co-culture for 7 days. (A) Western blot analysis of $\mathrm{HCN} 4$ protein expression in the transfected groups and neonatal rat ventricular cardiomyocytes (NRVMs). GAPDH was used as the protein control. (B) Quantitative assessment of HCN4 protein levels by integrated optical density analyses. (C) Expression of HCN4 mRNA in the transfected groups. ${ }^{*} \mathrm{P}<0.05$ vs. other groups.

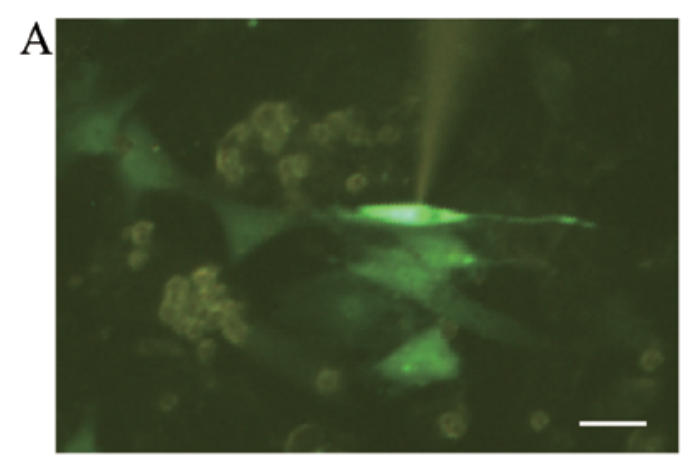

\section{B}
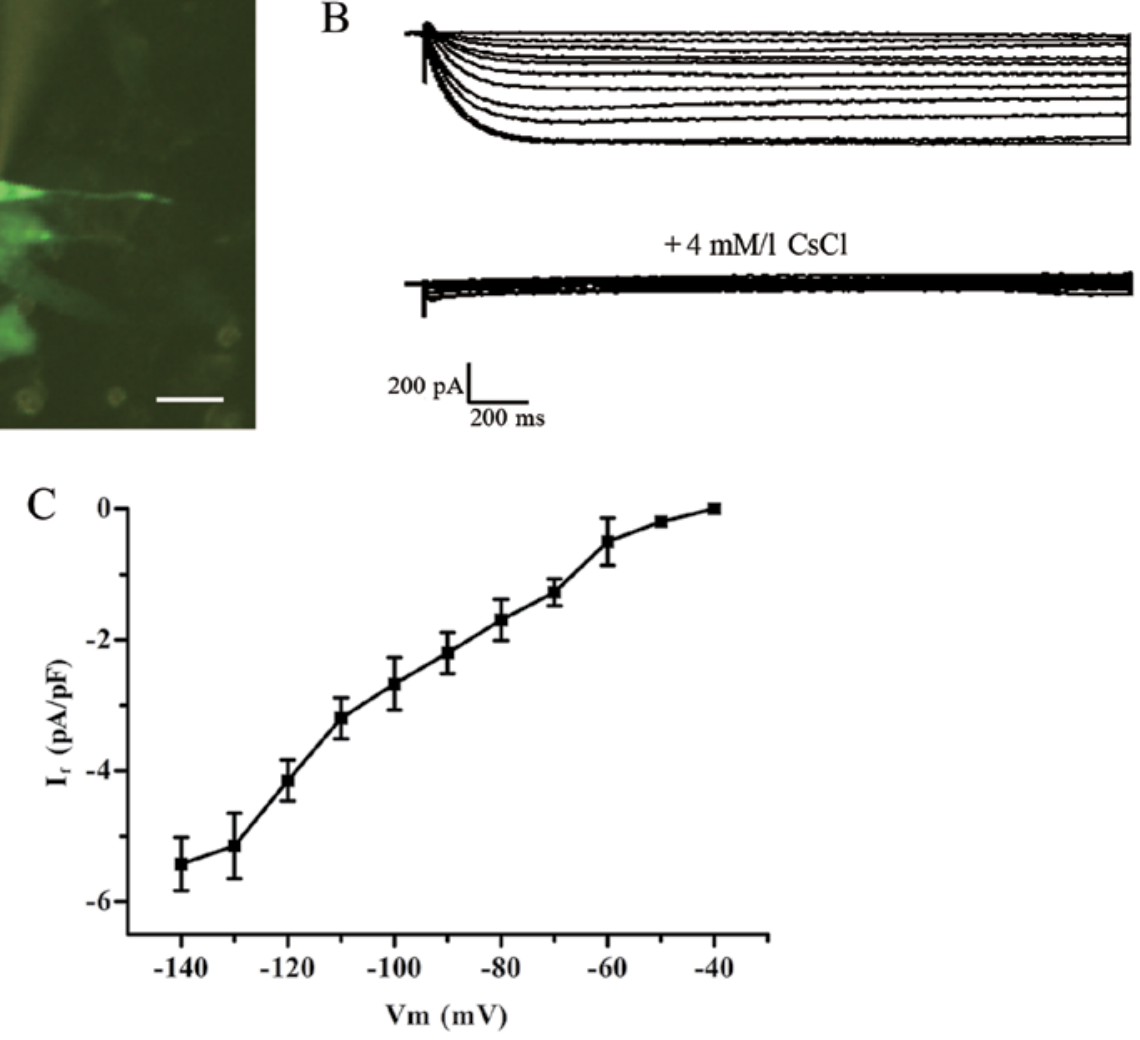

Figure 5. Detection of $I_{f}$ current using the patch clamp technique. (A) The spindle-shaped cell was used for electropysiological recordings. (B) Hyperpolarization-activated inward current in T-box 18 (TBX18)-adipose-derived stem cells (ADSCs) and was blocked by CsCl (4 mM/l). (C) Average current-voltage association of the $\mathrm{I}_{\mathrm{f}}$ current. Scale bar, $100 \mu \mathrm{m}$. 

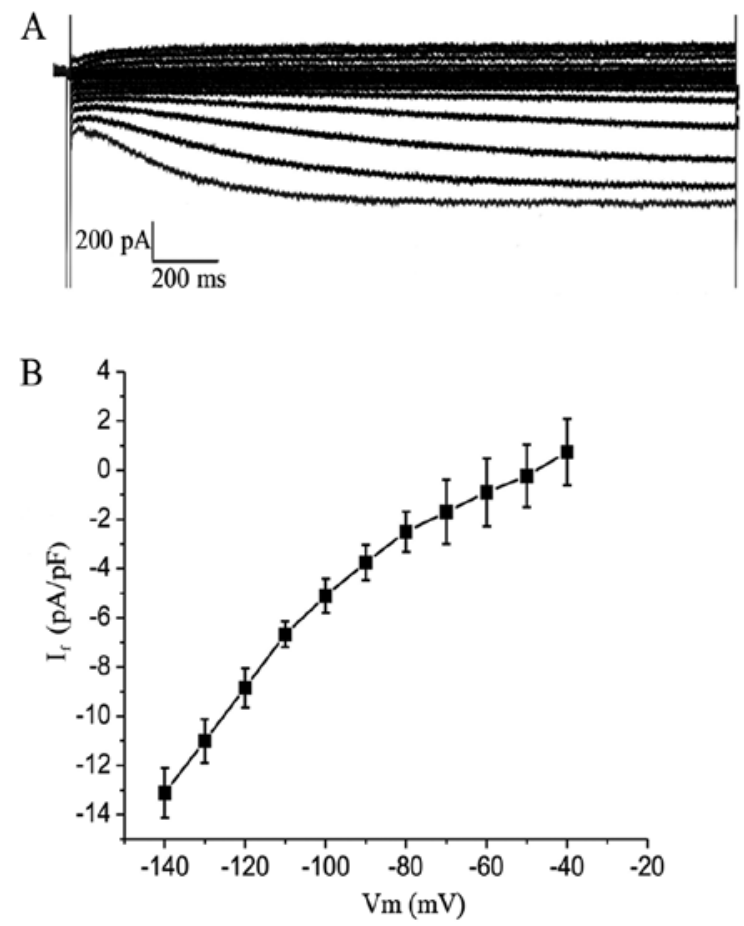

Figure 6. Identification of $I_{f}$ channels in human induced pluripotent stem cell-derived cardiomyocytes (hiPSCMs). (A) Macroscopic $\mathrm{I}_{\mathrm{f}}$ currents a in single beating hiPSCM using hyperpolarization-activated inward current. (B) Current-voltage relationship for $\mathrm{I}_{\mathrm{f}}$ channels was studied using whole-cell patch clamp techniques.

embryonic stem cells into pacemaker-like cells $(14,15)$. TBX18 delivered to cardiomyocytes may induce fully functional pacemaker cells, whereas TBX3 only induces pacemaker-like cells (16). One study found that bone marrow mesenchymal stromal cells transfected with the Shox 2 gene produced pacemaker-like cells in vitro (17). TBX18, TBX3 and SHOX2 are all embryonic transcription factors that regulate the development of the sinoatrial node. TBX18 is upstream of TBX3 and SHOX2 (6). This study also found that the TBX18 gene induces the formation of pacemaker-like cells. SHOX2, TBX18 and TBX3 may play a synergistic role in the regulation of HCN4 expression.

In this study, ADSCs were successfully transfected with the TBX18 gene. The transfected ADSCs were directly co-cultured with NRVMs at a 1:10 or 1:5 ratio in order to induce differentiation of the stem cells. Some studies have shown that direct contact with adult stem cells is essential for them to successfully differentiate into myocardial cells $(3,18,19)$. In the co-culture system, cells were induced to differentiate by cell factors, chemical substances, electrical activity and mechanical stretch (20). The expression of myocardial markers was higher after direct contact than after indirect contact of the two cell types (3). In this study, we found that ADSCs and NRVMs became connected to each other and that the TBX18-ADSCs and GFP-ADSCs generated synchronized beating with the syncytial NRVMs. This is consistent with previous findings (21). We also found that there was no significant difference between the two groups in the myocardial-like differentiation rate. The results showed that TBX18 does not affect the differentiation of ADSCs into cardiomyocytes.
In the present study, HCN4 expression was detected in the TBX18-ADSCs group by RT-qPCR and western blot analysis. HCN1, HCN2 and HCN4 are the main subtypes of the HCN gene in the heart (22). Sinoatrial node cells contain the highest proportion of HCN4 which plays an important role in phase 4 automatic depolarization of pacemaker cells (23). Previous studies have shown that ADSCs are capable of producing myocardial-like cells after being co-cultured with NRVMs $(3,24)$. However, there was no expression of pacemaker-related markers. We found that TBX18-ADSCs expressed HCN4. The voltage-clamp data showed that TBX18-ADSCs generated an $\mathrm{I}_{\mathrm{f}}$-like current after being co-cultured with NRVMs for 5-7 days, and $\mathrm{CsCl}$ significantly decreased the $\mathrm{I}_{\mathrm{f}}$ current. The occurrence of an $\mathrm{I}_{\mathrm{f}}$ current provides further evidence confirming the presence of pacemaker-like cells derived from TBX18-ADSCs. A previous study showed that ADSCs are capable of differentiating into pacemaker cells in methylcellulose medium; however, the differentiation rate reported was very low (5). The researchers found several pacemaker cells with phase 4 automatic depolarization. In this study, the underlying mechanism responsible for this differentiation may involve upregulation of the HCN4 promoter by TBX18 (9), which indirectly increases the expression of HCN4 and enhances the efficiency of the differentiation of ADSCs into pacemaker-like cells. In the present study, phase 4 automatic depolarization was not observed in TBX18-ADSCs. The first possible explanation for this negative finding is that the patch clamp method was performed after blocking electrical conduction. A recent study indicated that an $I_{f}$ current derived from stem cells flows into adjacent cardiomiocytes to depolarize cardiomyocytes to the threshold for a new action potential (25). When electrical conduction is blocked, automatic depolarization cannot occur. Secondly, it may due to the fact that automatic depolarization not only requires the participation of $\mathrm{I}_{\mathrm{f}}$ current but also $\mathrm{Ca}^{2+}$ channels T-type $\left(\mathrm{I}_{\mathrm{Ca}, \mathrm{T}}\right), \mathrm{Ca}^{2+}$ channels L-type $\left(\mathrm{I}_{\mathrm{Ca}, \mathrm{L}}\right)$ and $\mathrm{Na}^{+} / \mathrm{Ca}^{2+}$ exchanger $\left(\mathrm{I}_{\mathrm{NCX}}\right)$ (26). Another reason may be the early stage of myocardial differentiation or the immature cardiac fact; that TBX18-ADSCs show lower expression of If current compared with pure hiPSCMs as demonstrated in a previous study of inward rectified potassium channels $\left(\mathrm{I}_{\mathrm{K} 1}\right)(27)$.

In conclusion, this study successfully demonstrated that ADSCs transfected with the human TBX18 gene induced differentiation into pacemaker-like cells. TBX18 may enrich the efficiency of pacemaker-like cell differentiation by promoting the expression of HCN4. Taken together, these findings suggest that we may construct the biological pacing by regulating the upstream surface-related ion channel proteins.

\section{References}

1. Taha MF and Hedayati V: Isolation, identification and multipotential differentiation of mouse adipose tissue-derived stem cells. Tissue Cell 42: 211-216, 2010.

2. Palpant NJ, Yasuda S, MacDougald O and Metzger JM: Non-canonical Wnt signaling enhances differentiation of $\mathrm{Scal}^{+} / \mathrm{c}-\mathrm{kit}{ }^{+}$adipose-derived murine stromal vascular cells into spontaneously beating cardiac myocytes. J Mol Cell Cardiol 43: 362-370, 2007.

3. Choi YS, Dusting GJ, Stubbs S, Arunothayaraj S, Han XL, Collas P, Morrison WA and Dilley RJ: Differentiation of human adipose-derived stem cells into beating cardiomyocytes. J Cell Mol Med 14: 878-889, 2010. 
4. Bai X, Yan Y, Song YH, Seidensticker M, Rabinovich B Metzele R, Bankson JA, Vykoukal D and Alt E: Both cultured and freshly isolated adipose tissue-derived stem cells enhance cardiac function after acute myocardial infarction. Eur Heart J 31 : 489-501, 2010.

5. Planat-Bénard V, Menard C, André M, Puceat M, Perez A, Garcia-Verdugo JM, Pénicaud L and Casteilla L: Spontaneous cardiomyocyte differentiation from adipose tissue stroma cells. Circ Res 94: 223-229, 2004.

6. Wiese C, Grieskamp T, Airik R, Mommersteeg MT, Gardiwal A, de Gier-de Vries C, Schuster-Gossler K, Moorman AF, Kispert A and Christoffels VM: Formation of the sinus node head and differentiation of sinus node myocardium are independently regulated by Tbx18 and Tbx3. Circ Res 104: 388-397, 2009.

7. Zhou B, Ma Q, Rajagopal S, Wu SM,Domian I, Rivera-Feliciano J, Jiang D, von Gise A, Ikeda S, Chien KR, et al: Epicardial progenitors contribute to the cardiomyocyte lineage in the developing heart. Nature 454: 109-113, 2008.

8. Christoffels VM, Grieskamp T, Norden J, Mommersteeg MT Rudat $\mathrm{C}$ and Kispert A: Tbx18 and the fate of epicardial progenitors. Nature 458: E8-E10, 2009.

9. Kapoor N, Liang W, Marbán E and Cho HC: Direct conversion of quiescent cardiomyocytes to pacemaker cells by expression of Tbx18. Nat Biotechnol 31: 54-62, 2013

10. Hu YF, Dawkins JF, Cho HC, Marbán E and Cingolani E: Biological pacemaker created by minimally invasive somatic reprogramming in pigs with complete heart block. Sci Trans Med 6: 245ra94, 2014

11. Yang J, Song T, Wu P, Chen Y, Fan X, Chen H, Zhang J and Huang C: Differentiation potential of human mesenchymal stem cells derived from adipose tissue and bone marrow to sinus node-like cells. Mol Med Rep 5: 108-113, 2012.

12. Bai D, del Corsso C, Srinivas M and Spray DC: Block of specific gap junction channel subtypes by 2-aminoethoxydiphenyl borate (2-APB). J Pharmacol Exp Ther 319: 1452-1458, 2006.

13. Harks EG, Camiña JP, Peters PH, Ypey DL, Scheenen WJ, van Zoelen EJ and Theuvenet AP: Besides affecting intracellular calcium signaling, 2-APB reversibly blocks gap junctional coupling in confluent monolayers, thereby allowing measurement of single-cell membrane currents in undissociated cells. FASEB J 17: 941-943, 2003.

14. Ionta V, Liang W, Kim EH, Rafie R, Giacomello A, Marbán E and Cho HC: SHOX2 overexpression favors differentiation of embryonic stem cells into cardiac pacemaker cells, improving biological pacing ability. Stem Cell Rep 4: 129-142, 2015.

15. Jung JJ, Husse B, Rimmbach C, Krebs S, Stieber J, Steinhoff G, Dendorfer A, Franz WM and David R: Programming and isolation of highly pure physiologically and pharmacologically functional sinus-nodal bodies from pluripotent stem cells. Stem Cell Rep 2: 592-605, 2014
16. Bakker ML, Boink GJ, Boukens BJ, Verkerk AO, van den Boogaard $M$, den Haan $A D$, Hoogaars WM, Buermans HP, de Bakker JM, Seppen J, et al: T-box transcription factor TBX3 reprogrammes mature cardiac myocytes into pacemaker-like cells. Cardiovasc Res 94: 439-449, 2012.

17. Feng Y,Luo S and Zhiyuan S: Canine bone marrow mesenchymal stromal cells modified with Shox 2 gene rebuild biological pacemakers in vitro. Heart 99: A4, 2013.

18. Ball SG, Shuttleworth AC and Kielty CM: Direct cell contact influences bone marrow mesenchymal stem cell fate. Int J Biochem Cell Biol 36: 714-727, 2004.

19. Fukuhara S, Tomita S, Yamashiro S, Morisaki T, Yutani C, Kitamura S and Nakatani T: Direct cell-cell interaction of cardiomyocytes is key for bone marrow stromal cells to go into cardiac lineage in vitro. J Thorac Cardiovasc Surg 125: 1470-1480, 2003.

20. Schuleri KH, Boyle AJ and Hare JM: Mesenchymal stem cells for cardiac regenerative therapy. Handbook Exp Pharmacol 180: 195-218, 2007.

21. Zhu Y, Liu T, Song K, Ning R, Ma X and Cui Z: ADSCs differentiated into cardiomyocytes in cardiac microenvironment. Mol Cell Biochem 324: 117-129, 2009.

22. Stieber J, Hofmann F and Ludwig A: Pacemaker channels and sinus node arrhythmia. Trends Cardiovasc Med 14: 23-28, 2004.

23. Shi W, Wymore R, Yu H, Wu J, Wymore RT, Pan Z, Robinson RB, Dixon JE, McKinnon D and Cohen IS: Distribution and prevalence of hyperpolarization-activated cation channel $(\mathrm{HCN})$ mRNA expression in cardiac tissues. Circ Res 85: e1-e6, 1999.

24. Choi YS, Matsuda K, Dusting GJ, Morrison WA and Dilley RJ: Engineering cardiac tissue in vivo from human adipose-derived stem cells. Biomaterials 31: 2236-2242, 2010.

25. Chauveau S, Brink PR and Cohen IS: Stem cell-based biological pacemakers from proof of principle to therapy: a review. Cytotherapy 16: 873-880, 2014.

26. Lakatta EG, Maltsev VA and Vinogradova TM: A coupled SYSTEM of intracellular $\mathrm{Ca}^{2+}$ clocks and surface membrane voltage clocks controls the timekeeping mechanism of the heart's pacemaker. Circ Res 106: 659-673, 2010.

27. Doss MX, Di Diego JM, Goodrow RJ, Wu Y, Cordeiro JM, Nesterenko VV, Barajas-Martínez H, Hu D, Urrutia J, Desai M, et al: Maximum diastolic potential of human induced pluripotent stem cell-derived cardiomyocytes depends critically on I(Kr). PLoS One 7: e40288, 2012. 